\title{
Gas Chromatography \\ DETERMINATION OF VOLATILES IN MOUSE URINE BY HEADSPACE SOLID PHASE MICROEXTRACTION AND GAS CHROMATOGRAPHY-MASS SPECTROMETRY
}

\author{
Esther Arnáiz, Daniel Moreno, and Roberto Quesada \\ Departamento de Química, Facultad de Ciencias, Universidad de Burgos, \\ Burgos, Spain
}

The extraction and determination of volatile compounds in mice urine were performed using headspace solid-phase microextraction with by gas chromatographymass spectrometry. In order to optimize the extraction conditions, experimental design was applied. A sample volume of $108 \mu \mathrm{l}$, a temperature of $148.6^{\circ} \mathrm{C}$, and a time of 94 minutes were found to be the optimal conditions. Samples of male and female mouse urine were analyzed to determine volatile compound profiles. A total of 36 organic compounds including ketones, aldehydes, and terpenes were detected. The results revealed that compounds such as 2-isopropyl-4,5-dihydrothiazole, which is considered a male sexual pheromone, were only detected in male urine samples, whereas others like benzaldehyde were especially abundant in female mouse urine. A comparison of female samples corresponding to different stages of the estrous cycle was also performed.

Keywords: Experimental design; Gas chromatography-mass spectrometry (GC-MS); Headspace-solidphase micro-extraction (HS-SPME); Mouse urine; Volatile organic compounds

\section{INTRODUCTION}

Urine is a complex biological fluid with enormous potential as a source of biochemical information. Therefore, the development of methods for the analysis of urine is an important objective. Urine contains diverse chemicals and plays an important role as a communication tool among animals. Of particular importance are volatile and semi-volatile substances functioning as pheromones. Examples of the extraction of volatile compounds in both rodent and human urine have been reported in literature using different techniques such as purge-and-trap (Prieto et al. 2000) and organic solvents (Achimaran et al. 2010; Zaporozhets, Tsyrulneva, and Ischenko 2012; Hardt and Angerer 2000; Zhang et al. 2008). On the other hand, solid-phase microextraction (SPME) has gained popularity as a simple, selective,

Received 28 August 2013; accepted 28 September 2013.

Address correspondence to Roberto Quesada, Departamento de Química, Facultad de Ciencias, Universidad de Burgos, 09001, Burgos, Spain. E-mail: rquesada@ubu.es

Color versions of one or more of the figures in the article can be found online at www. tandfonline.com/lanl. 
and environmentally friendly tool for the sampling of a variety of volatile and semivolatile compounds in different matrices. SPME presents several advantages for the extraction process such as small sample volume and reduced interferences of the matrix leading to cleaner extracts. Thus, SPME serves as a useful analytical tool prior to gas and liquid chromatography analyses (Biniecka and Caroli 2011; Vas and Vékey 2004). Examples of the extraction of organic volatile compounds in diverse matrices such as environmental samples (Krutz, Senseman, and Sciumbato 2003), cosmetics (Alvarez-Rivera et al. 2013), food samples (Lee et al. 2013; Bryant and McClung 2011; Palma-Harris, McFeeters, and Fleming 2001; Kumari et al. 2013; Pozo-Bayón et al. 2001), and biological matrices (Aresta et al. 2008; Mills and Walker, 2001) have been published in literature.

The purpose of this study was to determine small volatile compounds present in mouse urine that may act as rodent pheromones and influence rodent behavior. HS-SPME is well suited to identify these compounds, as it has already been applied to identify pheromones in the glands of Lepidoptera (Frérot, Malosse, and Cain 1997), elephant urine (Kayali-Sayadi et al. 2003), and rodent urine (Dehnhard et al. 2003; Osada et al. 2008; Gutiérrez-García et al. 2007). From the experimental point of view, SPME techniques may be influenced by a relatively large number of factors. To address this issue, experimental design allows rational and systematic optimization of conditions leading to better and more reproducible results (Salafranca et al. 2003). The advantages of using experimental design applied to SPME extraction have been demonstrated for the determination of drugs in biological matrices in humans (Reubsaet et al. 1998) or organic compounds in water (Mousavi et al. 2007; De Lima Gomes et al. 2011). The goal of this study was to optimize the SPME conditions using experimental design to perform the analyses and to establish the best extraction conditions for volatile compounds in mouse urine samples.

\section{EXPERIMENTAL}

\section{Urine Samples}

Mouse urine samples were provided by Faculty of Medicine, University of Valladolid (Spain). All samples were stored at $-20^{\circ} \mathrm{C}$ following collection until analysis.

\section{Solid Phase Micro-Extraction}

$85 \mu \mathrm{m}$ StableFlex carboxen/polydimethylsiloxane (CAR/PDMS) fibers, a solid phase micro-extraction holder for manual use, and an SPME inlet guide were purchased from Supelco (Bellefonte, PA, USA). Head-space solid phase microextraction was performed in septum sealed vials. The urine was placed in sealed vials and diluted to a total volume of $1 \mathrm{ml}$ with a $\mathrm{NaCl}$ solution. Fibers were inserted through the septum and maintained $1 \mathrm{~cm}$ above of the samples which were heated and stirred during all the extraction process. After extraction, the fibers were desorbed for 15 minutes in the injector of the gas chromatograph system using manual injection, the SPME manual holder, and the inlet guide. Fibers were conditioned before use as recommended by the manufacturer and cleaned at $275^{\circ} \mathrm{C}$ 
for one hour in the injection port of the gas chromatograph. Blank extractions and analyses were performed in order to ensure correct identification.

\section{Chromatographic Conditions}

Analysis were performed using a 6890N Gas Chromatograph system coupled with a Mass Selective Detector 5975 supplied by Agilent Technologies Network. The injection port was equipped with a $0.75-\mathrm{mm}$ i.d. inlet liner (Supelco, Bellefonte, PA, USA) to optimize fiber desorption and sample delivery on the column (HP-1MS capillary column; $30 \mathrm{~m} \times 250 \mu \mathrm{m} \times 0.25 \mu \mathrm{m})$. Helium, at a flow rate of $1 \mathrm{ml} / \mathrm{min}$, was used as the carrier gas. The oven temperature program started at $35^{\circ} \mathrm{C}$. After 2 minutes, the temperature was increased to $80^{\circ} \mathrm{C}$ at $10^{\circ} \mathrm{Cmin}^{-1}$, to $250^{\circ} \mathrm{C}$ at $5^{\circ} \mathrm{Cmin}^{-1}$, and finally to $300^{\circ} \mathrm{C}$ at $20^{\circ} \mathrm{C} \mathrm{min}^{-1}$. This temperature was held for 10 minutes. The interface was maintained at $300^{\circ} \mathrm{C}$, the ion source at $230^{\circ} \mathrm{C}$, and the quadrupole analyzer at $150^{\circ} \mathrm{C}$. Electron impact (EI) spectra were obtained with an electron energy of $70 \mathrm{eV}$. Mass spectral acquisition was performed from 35 to $800 \mathrm{amu}$. The identity of the compounds was assigned according to the NIST (National Institute of Standards and Technology, Maryland, USA) database.

\section{RESULTS AND DISCUSSION}

\section{Experimental Design}

The optimal extraction conditions for the volatile compounds were established using experimental design implemented with the statistical program Statgraphics Centurion XVI.I. An orthogonal central composite design was selected involving three experimental factors (volume of sample, temperature, and time of extraction) and two response variables (the total peak area of the analytes of interest and the number of compounds detected). In order to obtain input data for the calculations, 16 experiments using male mouse urine samples were performed. The resulting Pareto charts are shown in Figure 1.

With respect to the total area response (Figure 1a), there are three effects with p-values less than 0.05 (volume, temperature, and the quadratic effect of time), indicating that they are significantly different from zero at the $95.0 \%$ confidence level. In the case of the number of peaks (Figure 1b), there is only one significant effect with $p$-value less than 0.05 , the temperature.

Surface response graphs were generated as a function of total peak area and number of compounds (Figure 2). Improved responses were obtained by increasing both the volume of sample and temperature of extraction.

Response surface modeling (RSM) was used in order to find the optimal conditions for the HS-SPME extractions (Figure 3). The desirability was found to increase with temperature and time whereas volume of sample should be above $60 \mu \mathrm{L}$ to optimize the extraction conditions. The optimal conditions were found to be a volume of $108 \mu 1,148.6^{\circ} \mathrm{C}$, and 94 minutes.

\section{Determination of Volatile Compounds in Mouse Urine}

Male and female mouse urine samples were analyzed under the optimized HS-SPME conditions. Moreover, female urine samples obtained at different stages 

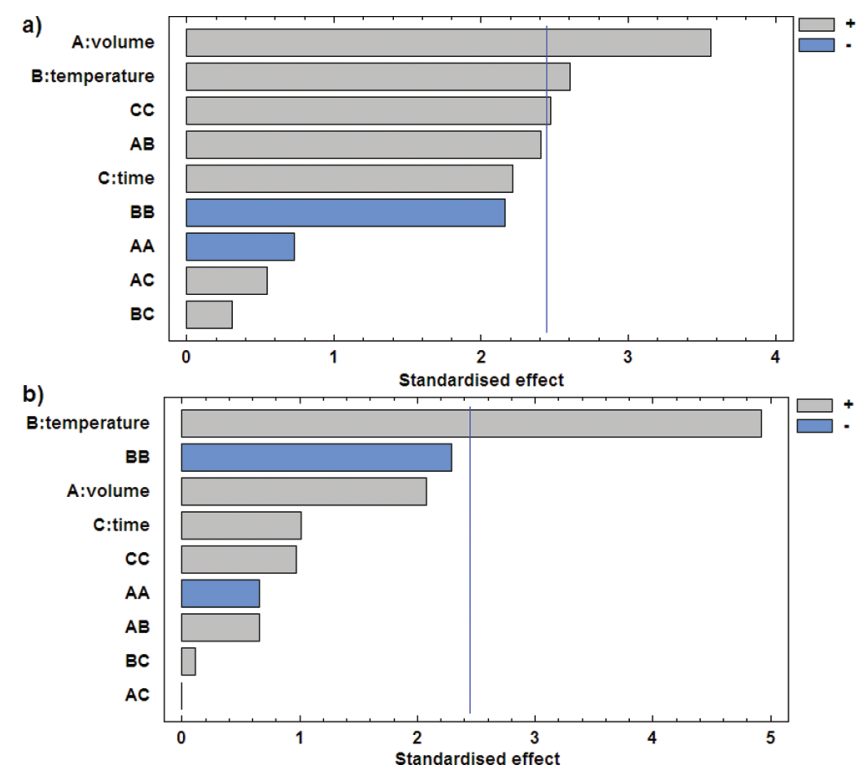

Figure 1. Pareto charts for the response variables: (a) total area and (b) number of compounds. of the estrous cycle were included in the study. Characteristic chromatograms corresponding to male and proestrus female mice urine samples are shown in Figure 4.

The results obtained in neutral extraction conditions, diluting urine samples with $\mathrm{NaCl}$ solution in order to increase the ionic force, are summarized in Table 1.
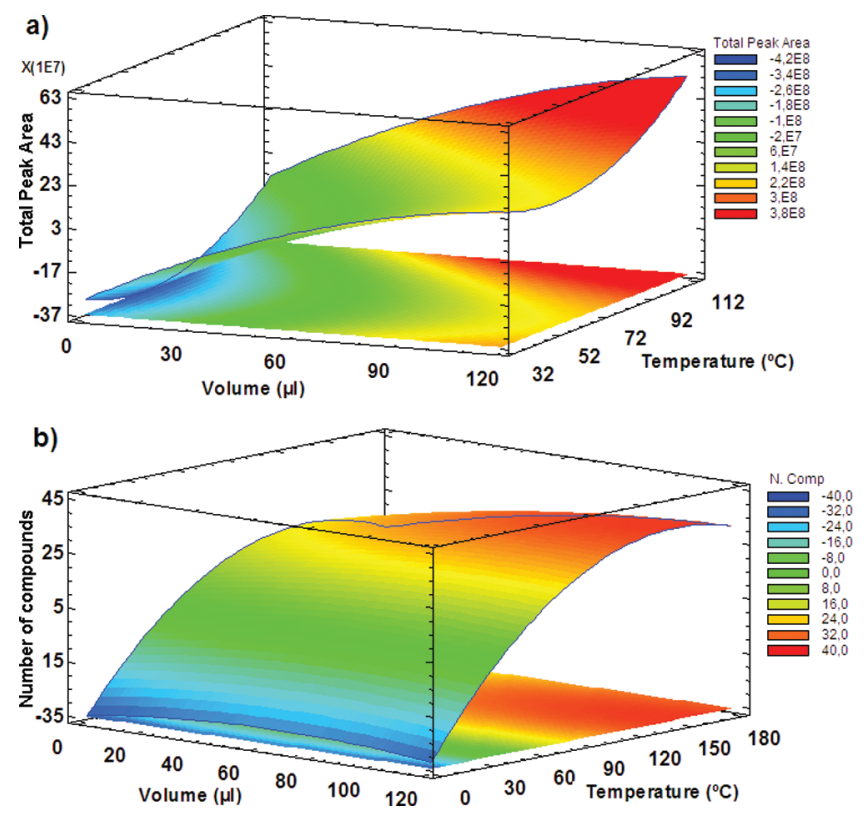

Figure 2. Surface response graphs: (a) total peak area and (b) number of compounds. 

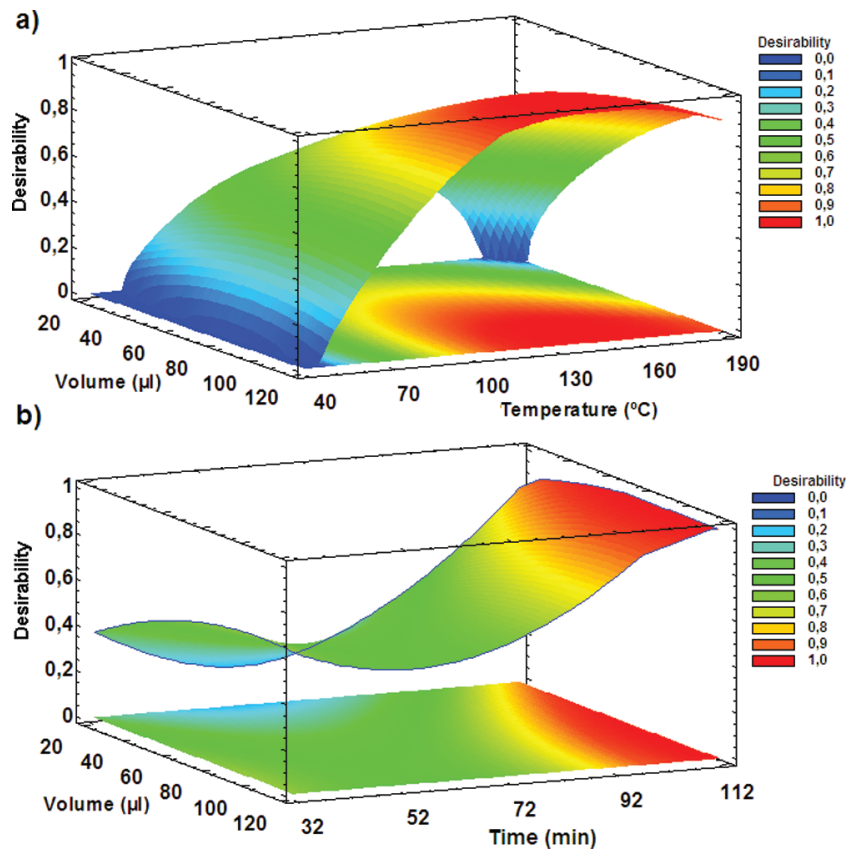

Figure 3. Response surface applied for the optimization of HS-SPME extractions.

The composition of the urine samples is expressed as percentages of the different compounds. The relative abundance of each compound was given as the ratio between the area of the target ion and the total area of all compounds.

A total of 36 organic compounds were identified in the urine samples. Twelve terpenes were identified. Seven compounds ( $\beta$-myrcene, linalool, geraniol, citral, $\beta$-farnesene, $\alpha$-farnesene, and farnesol) were satisfactorily identified, with farnesol most abundant. The profiles of the male and female samples, both male and female, are similar, although some significant differences were observed. The amount of benzaldehyde detected was much higher in female compared to male

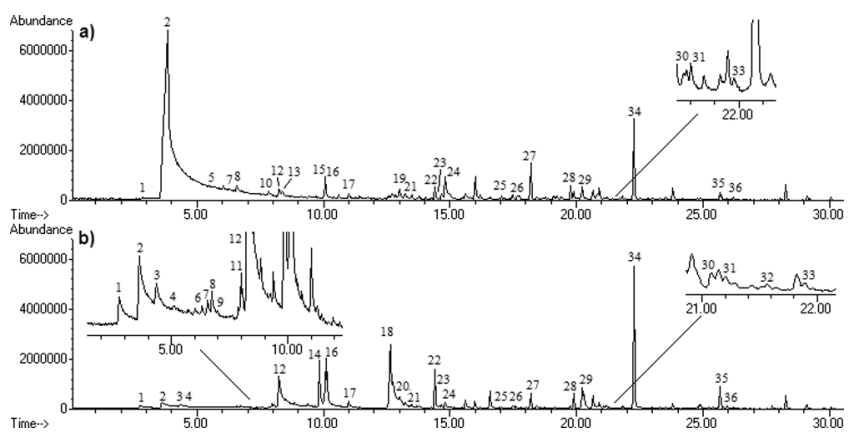

Figure 4. Representative total ion chromatograms of SPME extracts: (a) female mouse urine and (b) male mouse urine. 
Table 1. Relative abundances of identified substances in mouse urine

\begin{tabular}{|c|c|c|c|c|c|c|}
\hline \multirow[b]{3}{*}{$\mathrm{N}^{\circ}$} & \multirow[b]{3}{*}{ Compound name } & \multirow[b]{3}{*}{ Diagnostic ions m/z (A) } & \multicolumn{2}{|c|}{ Male } & \multicolumn{2}{|c|}{ Female } \\
\hline & & & \multicolumn{4}{|c|}{ Proestrus Diestrus Estrus } \\
\hline & & & $\%$ & $\%$ & $\%$ & $\%$ \\
\hline 1 & 3-hepten-2-one & 55 (100), 97 (86), 43 (70), $112(33)$ & 2.10 & 0.34 & 0.57 & 1.48 \\
\hline 2 & Benzaldehyde & $\begin{array}{l}106(100), 77(95), 105(90), 51 \\
\quad(48.9)\end{array}$ & 9.81 & 84.34 & 73.10 & 66.34 \\
\hline 3 & Dimethyl sulphide & $\begin{array}{l}126(100), 45(60), 79(50.6), 111 \\
(15)\end{array}$ & 1.74 & - & - & - \\
\hline 4 & 6-methyl-3-heptanone & $\begin{array}{l}57(100), 43(80), 72.05(60), 81 \\
\quad(54), 128(16)\end{array}$ & 0.09 & - & - & - \\
\hline 5 & 4-octen-3-one & 55 (100), $70(93), 43(18)$ & - & 0.07 & 0.28 & 0.37 \\
\hline 6 & 5-methyl-5-hepten-3-one & 57 (100), 41 (46), 69 (39), 97 (22) & 0.36 & - & 0.14 & 0.21 \\
\hline 7 & 2-pentyl furane & $81(100), 53(14), 138(21)$ & 0.73 & 0.17 & 1.39 & 1.61 \\
\hline 8 & Terpene 1 (-myrcene) & $\begin{array}{l}93(100), 41(66), 69(66), 79(15), \\
121(6)\end{array}$ & 0.65 & 0.11 & 0.28 & 0.31 \\
\hline 9 & $\begin{array}{l}\text { 2-isopropyl-4,5- } \\
\text { dihydrothiazole }\end{array}$ & $\begin{array}{l}60(100), 129(40), 114(15), 59.05 \\
\quad(25)\end{array}$ & 0.08 & - & - & - \\
\hline 10 & 3-octen-2-one & $\begin{array}{l}55(100), 43(90), 111(80), 126 \\
\quad(15)\end{array}$ & - & 0.46 & 0.50 & 0.78 \\
\hline 11 & $\begin{array}{l}\text { 3-ethyl-2-methyl-1,3- } \\
\text { hexadiene }\end{array}$ & 95 (100), 67 (91), 57 (79), 41 (56) & 1.40 & - & - & - \\
\hline 12 & 1-phenyl-ethanone & $\begin{array}{l}105(100), 77(68), 120(32), 95 \\
(20), 51(19)\end{array}$ & 33.93 & 1.35 & 2.99 & 3.22 \\
\hline 13 & Octanal & $\begin{array}{l}43(100), 56(75), 84(60), 69(25), \\
100 \\
\quad(10)\end{array}$ & - & 0.18 & 0.23 & 0.32 \\
\hline 14 & $\begin{array}{l}\text { 2-sec-butyl-4,5- } \\
\text { dihydrothiazole }\end{array}$ & $\begin{array}{l}115(100), 60(95), 59(25), 128.05 \\
\quad(19)\end{array}$ & 13.32 & - & - & 0.04 \\
\hline 15 & Nonanal & 57 (100), 44 (80), 98 (35), $70(25)$ & - & 0.11 & 0.19 & 0.23 \\
\hline 16 & Terpene 2 (linalool) & $\begin{array}{l}71(100), 93(90), 80(34), 115(32), \\
121(29), 136(10)\end{array}$ & 2.20 & 0.61 & 1.58 & 2.07 \\
\hline 17 & 3-nonen-2-one & $\begin{array}{l}55(100), 43(55), 71.10(23), 97 \\
(24), \\
125(41)\end{array}$ & 1.41 & 0.44 & 0.63 & 0.66 \\
\hline 18 & 3-methyl pyridine & 93(100), 65 (33), 79 (11), 43 (7), & 0.75 & - & - & - \\
\hline 19 & 4-pentyl-phenol & $\begin{array}{l}107(100), 108(88.2), 77(22.2), 27 \\
\quad(5.1)\end{array}$ & - & 1.12 & 2.07 & 2.67 \\
\hline 20 & N-phenyl-formamide & 43 (65), 93 (100), 87 (39), 121 (83) & 0.32 & - & - & - \\
\hline 21 & 2,3-dihydro-benzofurane & 120 (100), 91 (80), $107(30)$ & 2.00 & 0.11 & 1.35 & 1.73 \\
\hline 22 & Terpene 3 (geraniol) & $\begin{array}{l}69(100), 41(57), 93(24), 123(13), \\
111(8)\end{array}$ & 3.26 & 0.72 & 1.46 & 2.07 \\
\hline 23 & Terpene 4 (citral) & $\begin{array}{l}69(100), 41(75), 84(24), 121(13) \\
93(22)\end{array}$ & 0.44 & 0.07 & 0.12 & 0.14 \\
\hline 24 & 1H-indole & $\begin{array}{l}117(100), 89(30), 90(30), 91(10) \text {, } \\
\quad 43(10)\end{array}$ & 3.93 & 5.01 & 3.89 & 4.46 \\
\hline 25 & Ester of propanoic acid & $\begin{array}{l}71(100), 113(83), 43 \text { (64), } 56 \text { (53), } \\
\quad 98(24)\end{array}$ & 0.08 & 0.07 & 0.09 & 2.07 \\
\hline 26 & N-ethyl-benzenamine & $\begin{array}{l}106(100), 153(30), 77(14), 136 \\
(5)\end{array}$ & 0.52 & 0.04 & 0.09 & 0.14 \\
\hline 27 & $\begin{array}{l}\text { 2,6-bis(1,1-dimethyl-ethyl)- } \\
\text { phenol }\end{array}$ & $191(100), 149(36), 206(24)$ & 2.55 & 1.88 & 2.21 & 1.52 \\
\hline
\end{tabular}


Table 1. Continued

\begin{tabular}{|c|c|c|c|c|c|c|}
\hline 28 & Terpene 5 (-farnesene) & $\begin{array}{l}69(100), 41(53), 93(64), 133(35), \\
\quad 81(22)\end{array}$ & 1.80 & 0.28 & 0.68 & 0.75 \\
\hline 29 & $\begin{array}{l}\text { Unassigned (cyclohexanol } \\
\text { derivative) }\end{array}$ & $57(100), 123(41), 109(21), 85(20)$ & 3.07 & 0.63 & 1.44 & 1.63 \\
\hline 30 & Terpene 6 ( $\alpha$-farnesene) & $\begin{array}{l}93(100), 41(85), 69(80), 55(57), \\
107(52), 119(48)\end{array}$ & 0.22 & 0.03 & 0.08 & 0.09 \\
\hline 31 & Terpene 7 & $\begin{array}{l}69(100), 41(62), 93(93), 119(30), \\
161(34), 204(28)\end{array}$ & 0.22 & 0.03 & 0.07 & 0.10 \\
\hline 32 & Terpene 8 & $\begin{array}{l}69(100), 93.05(60), 107(22), 123 \\
\quad(14), 136(15),\end{array}$ & 0.06 & - & - & - \\
\hline 33 & Terpene 9 & $\begin{array}{l}93(100), 119(38), 109(28), 41 \\
\quad(29)\end{array}$ & 0.11 & 0.02 & 0.04 & 0.06 \\
\hline 34 & Terpene 10 (farnesol) & $\begin{array}{l}69(100), 41(57), 93(76), 107(46), \\
136(26), 204(3)\end{array}$ & 11.00 & 1.52 & 3.73 & 4.02 \\
\hline 35 & Terpene 11 & $\begin{array}{l}69(100), 41(59), 93(39), 79(17) \\
107(16) 121(11))\end{array}$ & 1.65 & 0.25 & 0.74 & 0.83 \\
\hline 36 & Terpene 12 & $\begin{array}{l}69(100), 84(48), 123(12), 41(44), \\
57(29)\end{array}$ & 0.20 & 0.03 & 0.08 & 0.08 \\
\hline
\end{tabular}

mice. Benzaldehyde was the main compound detected in all the stages of the female estrous cycle $(84.34 \%$ in proestrus, $73.10 \%$ in diestrus, and $66.34 \%$ in estrus), whereas in male urine samples, this percentage dropped to approximately $10 \%$. Percentages of phenyl ethanone in male urine samples (close to $34 \%$ ) were higher than those detected in females (1-3\% depending on their estrous cycle). All terpenes were detected in male and female mice, except that terpene 8 was found exclusively in males. The detected amount of terpenes was in general higher in males than in females. For instance, the farnesol percentage in males was found to be $11 \%$, whereas it decreased to $4 \%-1.5 \%$ in females. The same trend was observed for other terpenes such as $\beta$-farnesene (1.8\% in males, $0.28-0.75 \%$ in females), geraniol (3.26\% in males, $0.72-2.07 \%$ in females), and linalool (2.20\% in males, $0.61-2.07 \%$ in females).

Some compounds were detected exclusively in urine from one gender. Thus, dimethyl sulfide, 6-methyl-3-heptanone, 2-isopropyl-4,5-dihydrothiazole, 3-ethyl-2methyl-1,3-hexadiene, 3-methylpyridine, and $\mathrm{N}$-phenylformamide were found only in males. On the other hand, compounds like 4-octen-2-one, 3-octen-2-one, octanal, nonanal, and 4-pentylphenol were exclusively observed in females. Compounds considered as sexual pheromones in mice such as 2-isopropyl-4,5-dihydrothiazole and 2-sec-butyl-4,5-dihydrothiazol were also detected.

Urine samples collected at different stages of the female mice estrous cycle also showed similar profiles. However, a slightly increase in the percentage of ketones during the estrus stage was observed. This observation is in agreement with the experiments reported by Schwende, Wiesler, and Novotny (1984) in female rats during this stage. The sexual pheromone 2-sec-butyl-4,5-dihydrothiazole was also 


\section{CONCLUSIONS}

Experimental design was implemented using response surface methodology and applied to the analysis of mouse urine in order to determine the best conditions for the extraction of volatile and semi-volatile compounds using HS-SPME with GC-MS. The use of the optimized extraction conditions $\left(108 \mu 1,148.6^{\circ} \mathrm{C}\right.$, and 94 minutes) resulted in robust, reproducible results. 36 organic compounds were detected in those samples. Several differences were observed when comparing male and female mouse urine samples. Benzaldehyde was found to be the main compound detected in the female urine samples. Depending on the gender, specific compounds were detected. Thus, compounds such as 2-isopropyl-4,5-dihydrothiazole were exclusively detected in males whereas ketones like 4-octen-2-one, 3-octen-2-one were detected in females. This method may have future application for the determination of volatile and semi-volatile compounds in urine.

\section{FUNDING}

Financial support from the European Commission ([SME-2011-1] Research for SMEs, PiedPiper project, Grant agreement: 286852) is gratefully acknowledged.

\section{REFERENCES}

Achiraman, S., G. Archunan, P. Ponmanickam, K. Rameshkumar, S. Kannan, and G. John. 2010. 1-Iodo-2 methylundecane [1I2MU]: An estrogen-dependent urinary sex pheromone of female mice. Theriogenology 74: 345-353.

Alvarez-Rivera, G., T. De Miguel, M. Llompart, C. Garcia-Jares, T. Gonzalez Villa, and M. Lores. 2013. A novel outlook on detecting microbial contamination in cosmetic products: Analysis of biomarker volatile compounds by solid-phase microextraction gas chromatography-mass spectrometry. Anal. Methods 5: 384-393.

Aresta, A., C. D. Calvano, F. Palmisano, and C. G. Zambonin. 2008. Determination of clenbuterol in human urine and serum by solid-phase microextraction coupled to liquid chromatography. J. Pharm. Biomed. Anal. 47: 641-645.

Biniecka, M., and S. Caroli. 2011. Analytical methods for the quantification of volatile aromatic compounds. Trends Anal. Chem. 30: 1756-1770.

Bryant, R. J., and A. M. McClung. 2011. Volatile profiles of aromatic and non-aromatic rice cultivars using SPME/GC-MS. Food Chem. 124: 501-513.

De Lima Gomes, P. C., J. Y. Barletta, C. E. D. Nazario, Á. J. Santos-Neto, M. A. Von Wolff, C. M. R. Coneglian, G. A. Umbuzeiro, and F. M. Lancas. 2011. Optimization of in situ derivatization SPME by experimental design for GC-MS multiresidue analysis of pharmaceutical drugs in wastewater. J. Sep. Sci. 34: 436-445.

Dehnhard, M., J.-M. Hatt, K. Eulenberger, A. Ochs, and G. Strauss. 2003. Headspace solidphase microextraction (SPME) and gas chromatography-mass spectrometry (GC-MS) for the determination of $5 \alpha$-androst-2-en-17-one and -17ß-ol in the female Asian elephant: application for reproductive monitoring and prediction of parturition. J. Steroid Biochem. Mol. Biol. 84: 383-391.

Frérot, B., C. Malosse, and A.-H. Cain. 1997. Solid-Phase Microextraction (SPME): A New Tool in Pheromone Identification in Lepidoptera. J. High Resol. Chromatogr. 20: 340-342.

Gutiérrez-García, A. G., C. M. Contreras, M. R. Mendoza-López, O. García-Barradas, and J. S. Cruz-Sánchez. 2007. Urine from stressed rats increases immobility in receptor rats forced to swim: Role of 2-heptanone. Physiol. Behav. 91: 166-172. 
Hardt, J., and J. Angerer. 2000. Determination of dialkyl phosphates in human urine using gas chromatography-mass spectrometry. J. Anal. Toxicol. 24: 678-684.

Kayali-Sayadi, M. N., J. M. Bautista, L. M. Polo-Díez, and I. Salazar. 2003. Identification of pheromones in mouse urine by head-space solid phase microextraction followed by gas chromatography-mass spectrometry. J. Chromatogr. B 796: 55-62.

Krutz, L. J., S. A. Senseman, and A. S. Sciumbato. 2003. Solid-phase microextraction for herbicide determination in environmental samples. J. Chromatogr. A 999: 103-121.

Kumari, R., D. Kumar Patel, P. Chaturvedi, N. Ghazi Ansari, and R. Chandra Murthy. 2013. Solid phase micro extraction combined with gas chromatography-mass spectrometry for the trace analysis of polycyclic aromatic hydrocarbons in chocolate. Anal. Methods 5: $1946-1954$.

Lee, J. Y., S. M. Yu, H.-J. Sim, S. K. Ko, and J. Hong. 2013. Comparative profiling of volatile composition from different Acorus species by solid-phase microextraction-gas chromatography/mass spectrometry. Anal. Methods 5: 3675-3687.

Mills, G. A., and V. Walker. 2001. Headspace solid-phase microextraction profiling of volatile compounds in urine: application to metabolic investigations. J. Chromatogr. B 753: 259-268.

Mousavi, M., E. Noroozian, M. Jalali-Heravi, and A. Mollahosseini. 2007. Optimization of solid-phase microextraction of volatile phenols in water by a polyaniline-coated Pt-fiber using experimental design. Anal. Chim. Acta 581: 71-77.

Osada,K., T. Tashiro, K. Mori, and H. Izumi. 2008. The identification of attractive volatiles in aged male mouse urine. Chem. Senses 33: 815-823.

Palma-Harris, C., R. F. McFeeters, and H. P. Fleming. 2001. Solid-Phase Microextraction (SPME) Technique for Measurement of Generation of Fresh Cucumber Flavor Compounds. J. Agric. Food Chem. 49: 4203-4207.

Pozo-Bayón, M. A., E. Pueyo, P. J. Martín-Álvarez, and M. C. Polo. 2001. Polydimethylsiloxane solid-phase microextraction-gas chromatography method for the analysis of volatile compounds in wines. Its application to the characterization of varietal wines. J. Chromatogr. A 922: 267-275.

Prieto, M. J., V. Berenguer, D. Marhuend, and A. Cardona. 2000. Purge-and-trap gas chromatographic determination of styrene in urine and blood. Application to exposed workers. J. Chromatogr., B 741: 301-306.

Reubsaet, K. J., H. R. Norli, P. Hemmersbach, and K. E. Rasmussen. 1998. Determination of benzodiazepines in human urine and plasma with solvent modified solid phase micro extraction and gas chromatography; rationalization of method development using experimental design strategies. J. Pharm. Biomed. Anal. 18: 667-680.

Salafranca, J., C. Domeño, C. Fernández, and C. Nerín. 2003. Experimental design applied to the determination of several contaminants in Duero River by solid-phase microextraction. Anal. Chim. Acta 477: 257-267.

Schwende, F. J., D. Wiesler, and M. Novotny. 1984. Volatile Compounds associated with estrus in mouse urine: potential pheromone. Experientia 40: 213-215.

Vas, G., and K. Vékey. 2004. Solid-phase microextraction: a powerful sample preparation tool prior to mass spectrometric analysis. J. Mass Spectrom. 39: 233-254.

Zaporozhets, O., I. Tsyrulneva, and M. Ischenko. 2012. Determination of 8 diuretics and probenecid in human urine by gas chromatography-mass spectrometry: Confirmation procedure. Am. J. Anal. Chem. 3: 320-327.

Zhang, J.-X., L. Sun, J.-H. Zhang, and Z.-Y. Feng. 2008. Sex- and gonad-affecting scent compounds and 3 male pheromones in the rat. Chem. Senses 33: 611-621. 